\title{
Takhayul pada Produk terhadap Kinerja Pemasaran
}

\author{
Adek \\ Akademi Maritim Nasional Jakarta Raya \\ Email: adek_lie@amanjaya.ac.id \\ Agung Kwartama \\ Akademi Maritim Nasional Jakarta Raya \\ Email:agung@amanjaya.ac.id \\ Sumiyatiningsih \\ Akademi Maritim Nasional Jakarta Raya \\ Email : sumiyatiningsih@amanjaya.ac.id \\ Didik Indriawan \\ Akademi Maritim Nasional Jakarta Raya \\ Email: Didik@amanjaya.ac.id
}

\begin{abstract}
This study aims to determine the influence of superstition on marketing performance that is intervening by the product, The study population is business owners who are superstitious for products. The research sample was 200 respondents taken using purposive sampling techniques and data collection methods using questionnaires. The research method used is descriptive statistics using the Lisrel application version 8.80 to process and analyze Structural Equation Modeling data. The results showed that a significant influence was superstition on the product; the significant influence of product superstition on marketing performance; no significant superstitious influence on marketing performance. Keywords: Superstitious, marketing performance, product
\end{abstract}

\begin{abstract}
Abstrak
Penelitian ini bertujuan untuk mengetahui pengaruh takhayul terhadap kinerja pemasaran yang dimoderasi produk. Jenis penelitian menggunakan pendekatan kuantitatif deskriptif. Populasi penelitian ini adalah pemilik bisnis yang percaya takhayul untuk produk. Sampel penelitiannya adalah 200 responden yang diambil dengan menggunakan teknik purpose sampling dan metode pengumpulan data menggunakan kuesioner. Metode penelitian yang digunakan adalah statistik deskriptif menggunakan aplikasi Lisrel versi 8.80 untuk mengolah dan menganalisis data Structural Equation Modeling. Hasil penelitian menunjukan bahwa pengaruh yang signifikan takhayul terhadap produk; pengaruh yang signifikan takhayul produk terhadap kinerja pemasaran; tidak adanya pengaruh yang signifikan takhayul terhadap kinerja pemasaran. Kata kunci: Takhayul, Kinerja pemasaran, Produk
\end{abstract}

\section{Pendahuluan}

Persaingan pemasaran produk di era revolusi industri versi 4.0 semakin tidak dapat dihindari dan semakin ketat seiring bertambahnya jumlah pelaku bisnis yang menjual produk di pasar tradisional maupun di dunia maya, maka perlu keterlibatan emosi dan minat dalam implementasi inovasi produk yang dilakukan oleh pebisnis dan juga dibutuhkan berbagai inovasi yang kreatif dalam menentukan strategi pemasaran produk untuk memenangan persaingan dan bagaimana memanfaatkan peluang untuk memenangkan persaingan pemasaran yang semakin kompetitif serta meningkatkan dan mempetahankan pemasaran berkelanjutan dalam menghadapi tantangan yang ada akan berpengaruh pada kinerja pemasaran. 
Peluang memenangkan persaingan bisnis yang kompetitif dan meningkatkan kemampuan pebisnis untuk memelihara kekuatannya dalam menghadapi tantangan yang ada berpengaruh pada kinerja dan keberhasilan bisnis yang dikelola (Hill dan McGowan, 1999). Terutama meningkatkan kinerja pemasaran dengan pendekatan pada budaya yakni percaya takhayul sebagai alternatif solusi untuk memecahkan persoalan yang tidak dapat di pecahkan oleh akal sehat (rasional), irrasional, dan nilai-nilai budaya dalam pemasaran produk (Kaur dan Chawla, 2016).

Dalam rangka meningkatkan kinerja pemasaran pebisnis perlu stimulus dalam meningkatkan daya jual produk yang mempunyai nilai tambah dan daya tarik bagi konsumen. Suatu produk menjadi menarik, jika terdapat dimensi kualitas, merek, kemasan, bentuk, label, etika estetika, warna, jaminan dan harga (Kotler dan Keller, 2012; Stanton,2008).

Beberapa daya jual produk yang dikaitkan dengan takhayul, seperti nama merek Coca Cola yang tidak memiliki nama resmi Tiongkok, sehingga para penjual dan pembeli menyebutnya dengan ejaan "ke-kou-ke-la" yang berarti 'menggigit kecebong lilin" atau 'kuda betina diisi lilin". Selanjutnya pengucapannya yang dianggap lebih baik diubah menjadi "ke-kou-ke-le" yang berarti "kebahagiaan ada di mulut". (Wang, Goodfellow dan Zhang, 2000). Begitu juga yang terjadi di negara Indonesia, yaitu sandal G-20179 merek Glacio estetika dan desain motif pada alas kaki yang dipercaya tulisan mirip kaligrafi surat al iklash (https://kaltim.tribunnews.com - Senin 8 Juli 2019).

Hal ini menunjukkan beberapa pelaku bisnis dalam memasarkan produk yang dijual masih percaya pada kekuatan takhayul yang memiliki konotasi positif dan perlu memperhatikan atau menghindar makna yang memiliki konotasi negatif pada nama merek dagang, warna, kemasan, desain dan estetika yang akan membawa keberuntungan. Selain itu juga memiliki nilai jual dan peranan dalam proses pemasaran serta penyampaian barang dan jasa yang diinginkan kepada konsumen agar tujuan akhir tercapai, yaitu keputusan konsumen membeli produk.

Hasil penelitian Kramer dan Block (2008) dengan menggunakan populasi mahasiswa University of Taiwan dengan sampel 50 koresponden dan terdapat pengaruh signifikan antara takhayul dengan keputusan membeli produk yang menggunakan warna dan angka keberuntungan sebagai atribut produk. Begitu juga hasil penelitian Chau, et al (2001).di Hongkong menggunakan populasi masyarakat Tiong hoa - Kanton, menyatakan terdapat hubungan yang signifikan antara penjualan apartement dengan nomor lokasi yang menggunakan angka yang dinyakinkan membawa keberuntungan.

Evgeny dan Pokryshevskaya, (2015) di Saint Petersburg - Rusia, menggunakan data sekunder data penjualan apartemen dengan sampel 201 data, menyatakan bahwa angka 7 merupakan simbol keberuntungan bagi penghuni atau pemilik apartemen pengaruhnya sangat signifikan terhadap produk yang dijual. Begitu juga hasil penelitian Slamet dan Tunjungsari (2012) di Indonesia dengan 200 data kuesioner, bahwa kesediaan membeli produk mobil sangat dipengaruh warna mobil yang dinyakinkan akan membawa keberuntungan. 
Dinamika di atas mengindikasikan adanya sebagian pemilik perusahaan yang percaya pada takhayul yang dikaitkan dengan produk yang dipasarkan, Apalagi dinamika tersebut sangat dipengaruhi budaya dan lingkungan pelaku bisnis dalam meningkatan kinerja pemasaran yang berkelanjutan, mempertahankan pelanggan setia dan memberi dampak pada pemenangkan persaingan, profitabilitas serta peningkatan penjualan produk sebagai tujuan akhir pebisnis.

Berdasarkan latar belakang masalah tersebut, peneliti tertarik untuk melakukan penelitian dan kajian teori yang lebih mendalam perihal sejauh mana hubungan percaya takhayul dengan produk yang memiliki makna berkonotasi positip serta sejauh mana hubungan antara percaya takhayul dengan kinerja pemasaran di moderasi produk oleh pejual kaos dan kemeja keturunan etnis Thiong hoa di pasar grosir jakata.

\section{Literature Review}

\subsection{Produk}

Menurut Stanton (2008), produk adalah yang berwujud maupun tidak berwujud termasuk di dalamnya, yaitu: 1). Kemasan menampilkan image dan pandangan terhadap suatu isi produk dan sebagai pelindung produk. 2). Warna dapat mendorong persepsi alam bawah sadar serta perilaku para konsumen dan mempengaruhi desain kemasan produk yang akan dipasarkan kepada para konsumen. 3). Harga, memiliki peranan yang sangat penting

dalam mempengaruhi keputusan konsumen dalam membeli produk, sehingga sangat menentukan keberhasilan pemasaran suatu produk. 4). Kualitas produk menunjukkan adanya, a). kinerja produk berhubungan dengan karakteristik operasi dasar dari sebuah produk, b). daya tahan produk, c). kesesuaian produk memenuhi spesifikasi tertentu dari konsumen atau tidak ditemukannya cacat pada produk. d). fitur produk yang dirancang untuk menyempurnakan fungsi produk atau menambah ketertarikkan konsumen terhadap produk. e). Estetika penampilan produk bisa dilihat dari tampak, rasa, bau, dan bentuk dari produk. 5). Merek, merupakan identitas produk guna mempermudah operasi pemasaran produk, meningkatkan nilai kualitas dan keawetan produk dan menambah daya penampilan produk. 6). Jasa dan reputasi penjualan, maksudnya menjaga nama baik produk, nama baik toko yang menjual dan jasa pelayanan pabrik maupun jasa pelayanan pengecer yang diterima oleh pembeli guna memuaskan kebutuhan dan keinginan.

Menurut Kotler dan Keller (2012), atribut yang menyertakan dan melengkapkan produk adalah: 1). Merek sebagai nama, tanda, simbol, desain, atau kombinasi hal-hal tersebut ditujukan untuk mengidentifikasi dan membedakan barang atau layanan suatu penjual dari barang dan layanan penjual lain dan keberadaan merek bermanfaat bagi pembeli, konsumen maupun bagi penjual, sebab merek (Gronroos, 2011) yang melekat di benak konsumen merupakan suatu tanggapan jangka panjang yang relevan dalam memori konsumen tersebut. 2). Kemasan adalah bahan pembungkus yang bersentuhan langsung dengan produk dan sekaligus juga sebagai identitas produk. Lewat kemasan yang berpenampilan unik, memiliki seni dan estetika yang dapat memenangkan hati konsumen serta konsumen tertarik untuk membeli produk yang sesuai harapannya. 3). Kualitas Produk adalah keseluruhan ciri dari suatu produk atau jasa yang ditawarkan dan mampu untuk memuaskan kebutuhan yang dinyatakan dalam bentuk tindakan atau pelayanan, tersirat pada kesesuaian dengan persyaratan, kecocokan untuk pemakaian, 


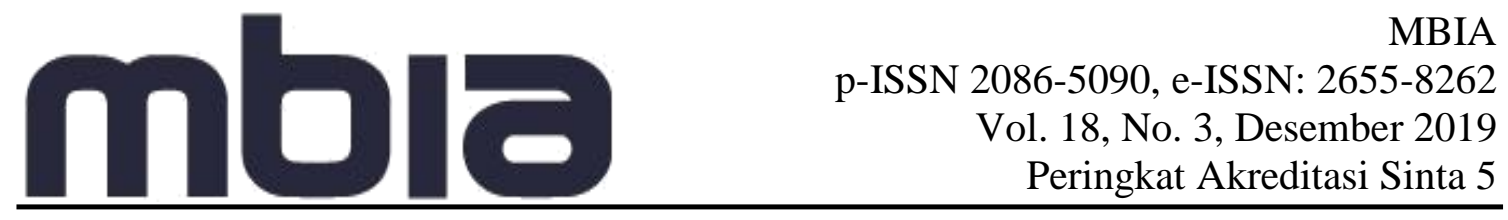

perbaikan berkelanjutan, bebas dari kerusakan atau cacat serta pemenuhan kebutuhan konsumen sejak awal dan setiap saat.

Variabel produk dibatasi menjadi 4 dimensi yaitu merek, kemasan, warna dan estetika.

\subsection{Takhayul.}

Takhayul adalah percaya pada kekuatan gaib atau percayaan kepada sesuatu yang dianggap ada atau oleh sebagian orang sakti, tetapi sebenarnya tidak ada atau tidak sakti bagi orang lain yang dilakukan secara turun menurun (Geertz, 1989; Koentjaraningrat, 2013). Ciri-ciri konsep takhayul menurut Levitt (1952) adalah (1) takhayul secara fundamental irrasional; (2) takhayul diterima dikalangan masyarakat tertentu. (3) takhayul mempengaruhi perilaku yang percaya; (4) takhayul bisa menjadi kepercayaan

(5) takhayul tidak memiliki bukti kuat (6) takhayul muncul secara spontan dan menyebar tanpa pernah mendapat sanksi.

Wang, et al. (2012) mengelompokan faktor-faktor yang mempengaruhi dimensi mempercaya takhayul menjadi 7 (tujuh) bagian, yaitu; 1). Percaya takdir yang dimaksud takdir adalah sarana untuk menjelaskan mengapa peristiwa tertentu terjadi dan terjadinya diluar kendali dan rencana manusia. 2). Percaya ramalan. Ramalan mengambarkan suatu usaha untuk memprediksi masa depan atau menafsirkan suatu pertanda pada merek Logo yang akan terjadi dimasa depan. 3). Percaya dukun. (Koentjaraningrat 2013; Hogendoorn, 1993). Dukun hanya bisa menginterpretasikan suatu takhayul yang terdapat dalam merek tertentu dan makna yang tersirat dalam merek logo atau nama bisnis. 4). Percaya Sihir (Koentjaraningrat 2013; Hogendoorn, 1993) atau fiksi yang terjadi tidak ada penjelasan yang dibenarkan dalam ilmiah, akan tetapi pada penelitian sebelumnya menunjukkan sihir yang mendorong dan memainkan peran unik dalam prilaku konsumen, seperti konsumen yang hedonis dan konsumen menjadi komsumsi sebagai ritualitik. 5). Legenda rakyat, cerita rakyat yang berisikan informasi untuk memperingatkan masyarakat akan potensi yang berbahaya 6). Percaya keberuntungan (Fortin, et al 2014; Wang, et al 2012). Sesuatu yang memilik pesona keberuntungan atau jimat keberuntungan bagi pemilik usaha dan memberikan pesona keberuntugan kepada konsumen. 7). Percaya ritual takhayul ( Sen dan Yesilyurt, 2014). Ritual takhayul digunakan untuk mengurangi kecemasan meningkatkan percaya diri akan keberhasilan, ketika ketidakpastian informasi dan kondisi pasar yang dijawab dengan keberhasilan penjualan produk di masyarakat.

Variabel takhayul dibatasi menjadi 4 dimensi dalam penelitian ini, yaitu 1).percaya keberuntugan 2). Percaya Dukun. 3). Ritual takhayul.

\subsection{Kinerja pemasaran.}

Peningkatan kinerja pemasaran merupakan salah satu tujuan strategi pemasaran yang dilakukan oleh pebisnis untuk selalu mengarah pada perbaikan kinerja. Kinerja pemasaran akan lebih baik, apabila dikaitkan dan memperhatikan takhayul yang dinyakinkan konsumen (Wang et al, 2012), Hal ini menyangkut keyakinan, perasaan stabilitas emosional dan menambah percaya diri untuk meningkatkan volume penjualan yang diikuti peningkatan jumlah konsumen serta mampu melakukan penetrasi pasar dalam keberhasilan dan pencapaian kinerja pemasaran yang baik (Grønholdt dan Martensen, 2006), Kinerja pemasaran juga dipengaruhi oleh kemampuan pemilik usaha mengimbangi dan mengikuti 
perubahan yang terus menerus pada lingkungan dan kondisi pasar. Prestasi yang dicapai oleh bagian pemasaran dalam suatu organisasi bisnis dapat dilihat hakekat dari kinerjanya, yaitu; pertumbuhan jumlah konsumen, volume penjualan dan memberikan profitabilitas yang maksimal.

Evgeny dan Pokryshevs (2015), menyimpulkan bahwa cara menilai hasil kinerja pemasaran dapat dilihat dari dimensi sebagai acuannya, yaitu; 1). Volume penjualan menunjukkan jumlah uang yang diterima ataupun unit produk yang terjual mengalami peningkatan atau penurunan, bila dibandingkan dengan volume penjualan pada periode tahun sebelumnya. 2). Pertumbuhan konsumen menunjukkan seberapa besar kenaikan konsumen yang kembali membeli produk yang sama dibandingkan satuan waktu tertentu. 3). laba menunjukkan peningkatan volume penjualan dan pertumbuhan konsumen yang berdampak positif pada pertumbuhan produksi dan mendapatkan hasil penjualan sebagai budaya bisnis.

\section{Metodologi Penelitian}

Objek penelitian ini adalah atribut-atribut produk, berupa merek, warna, kemasan dan estetika yang terdapat pada kaos dan kemeja serta ditujukan kepada pebisnis yang percaya takhayul yang terkait dengan atribut-atribut produk yang bisa meningkatkan kinerja pemasaran. Populasi dalam penelitian ini adalah pebisnis keturunan Thiong hoa yang menjual produk kaos dan kemeja di pasar grosir Jakarta. Jumlah sampel yang digunakan minimal 200 sampel. Teknik sampling adalah non probabilitas, yaitu tidak memberi peluang atau kesempatan yang sama kepada setiap populasi untuk dipilih menjadi anggota sampel (Sekaran dan Bougie, 2013), dan metode analisis sampel menggunakan purpose sampling dengan kriteria pebisnis yang menjual kaos atau kemeja di pasar grosir di wilayah Jakarta

Jenis penelitian ini menggunakan kuantitatif dan deskriptif, tujuannya memberikan atau menjabarkan suatu keadaan atau fenomena yang terjadi saat ini dengan menggunakan prosedur ilmiah untuk menjawab masalah secara aktual. Sumber data primer diperoleh dari hasil menyebarkan kusioner dan wawancara pemilik usaha dari tanggal 1 sampai dengan 28 Pebruari 2019, sedangkan data sekunder berupa studi literatur, websites, internet dan jurnal membahas tentang takhayul, produk dan kinerja pemasaran. Pengukuran setiap variabel menggunakan skala likert dengan metode analisis Structural Equation Modelling.

\section{Hasil dan Pembahasan}

\subsection{Hasil analisys Deskriptif}

Deskriptif statistik yang disajikan dalam bentuk persentase atau proporsi merupakan hasil jawaban indikator pertanyaan kuesioner yang masih dianggap bermasalah atau belum positif hasil perhitungannya. Indikator-indikator yaitu: (a) Pengusaha belum melakukan konsultasi dengan dukun; (b) Pengusaha belum menggunakan simbol yang dianggap kurang etika untuk merek dagang; (c) Pengusaha belum menggunakan gambar estetika yang dianggap melanggar norma-norma agama; (d) Pengusaha belum menggunakan merek yang menggambarkan sesuatu mengenai manfaat produk yang dijual. 


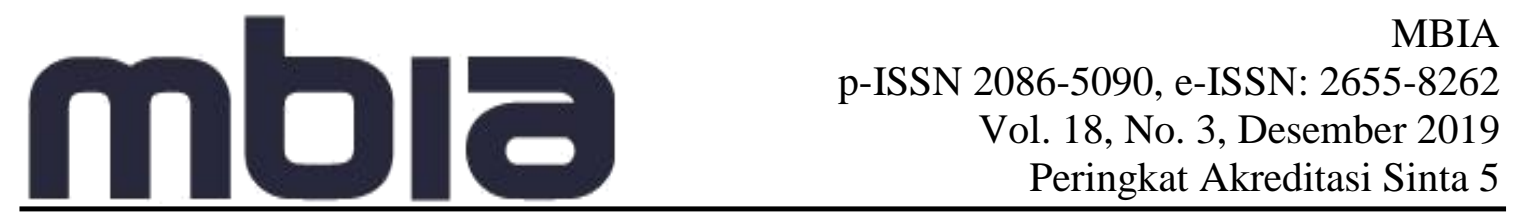

\subsection{Hasil Uji Pretest}

Hasil uji pretest yang dilakukan pada 30 responden menggunakan program SPSS Versi.21 menunjukkan item kuisioner yang valid dan reliable.

\subsection{Hasil Uji Struktur Model}

Tabel 1. Hasil Uji Struktur Model

\begin{tabular}{|c|c|c|c|c|}
\hline & Ukuran & Kriteria fit & Hasil Hitung & Kesimpulan \\
\hline \multirow{4}{*}{$\begin{array}{c}\text { Absolute fit } \\
\text { indices }\end{array}$} & $\chi^{2}$ & $\geq 0,05$ & 145,68 & Fit \\
\hline & GFI & $>0,90$ & 0,88 & Marginal Fit \\
\hline & $\begin{array}{l}\text { RMSEA } \\
\mathrm{p}\end{array}$ & $\begin{array}{l}\leq 0.08 \\
\geq 0,05\end{array}$ & $\begin{array}{l}0,12 \\
0,00\end{array}$ & Tidak Fit \\
\hline & RMR & $\leq 0,05$ & 0,06 & Tidak Fit \\
\hline \multirow{5}{*}{$\begin{array}{l}\text { Incremental } \\
\text { fit indices }\end{array}$} & AGFI. & $\geq 0,90$ & 0,80 & Marginal Fit \\
\hline & NFI & $\geq 0,90$ & 0,89 & Marginal Fit \\
\hline & IFI & $\geq 0,90$ & 0,91 & Fit \\
\hline & RFI & $\geq 0,90$ & 0,85 & Marginal Fit \\
\hline & CFI & $\geq 0,90$ & 0,91 & Fit \\
\hline \multirow{4}{*}{$\begin{array}{l}\text { Parsimony } \\
\text { fit indices }\end{array}$} & PNFI & $\begin{array}{l}\text { Semakin tinggi } \\
\text { semakin baik }\end{array}$ & 0,63 & Tidak Fit \\
\hline & PGFI. & $\begin{array}{l}\text { Semakin tinggi } \\
\text { Semakin baik }\end{array}$ & 0,51 & Tidak fit \\
\hline & AIC & $\begin{array}{l}\text { Nilai AIC < Nilai } \\
\text { Independence AIC }\end{array}$ & $\begin{array}{c}\text { AIC }(177,49)< \\
\text { Independence AIC } \\
(1380,42) \\
\end{array}$ & Fit \\
\hline & CAIC & $\begin{array}{c}\text { Nilai CAIC < Nilai } \\
\text { Saturated dan } \\
\text { independence } \\
\text { CAIC }\end{array}$ & $\begin{array}{c}\text { CAIC }(276,36)<\text { Saturated } \\
(346,41) \text { dan Independence } \\
(14223,41)\end{array}$ & Fit \\
\hline
\end{tabular}

Sumber: Data yang Diolah, 2019

Berdasarkan Tabel 1.1.Hasil uji struktur model terdapat delapan ukuran Goodnes of Fit yang menunjukan kecocokan yang baik dan lima ukuran Goodness-of-fit yang menunjukkan kecocokan yang kurang baik, sehingga dapat disimpulkan bahwa kecocokan keseluruhan model telah memenuhi tingkat pengukuran dan kesesuaian model. Hal ini telah sesuai dengan pernyatakaan Hair, et al (2014), bahwa penggunaan minimal 4 (empat) ukuran yang memadai dari kriteria Goodness-of-fit sudah terwakilkan. 


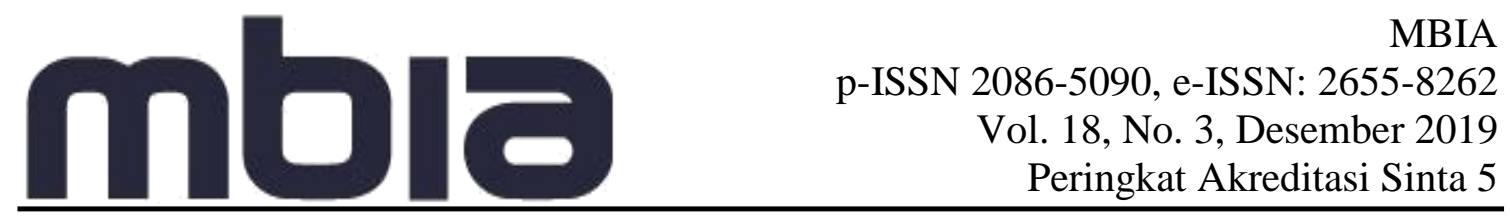

\subsection{Hasil uji pengaruh antar variable}

Gambal 1.1.: Hubungan antar Variabel.

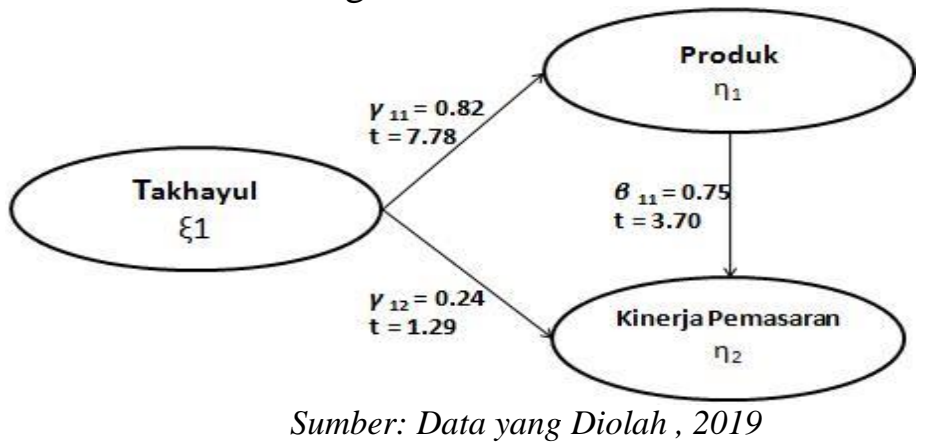

Tabel 2. Pengaruh Lansung Antar Variabel

\begin{tabular}{|l|c|c|c|l|}
\hline \multicolumn{1}{|c|}{ Antar Variabel } & $\begin{array}{c}\text { Determinasi } \\
\left(\mathrm{R}^{2}\right)\end{array}$ & $\begin{array}{c}\text { Nilai } \\
\text { Estimasi }\end{array}$ & $\begin{array}{c}\text { Nilai } \\
\text { Statistik t }\end{array}$ & \multicolumn{1}{|c|}{ Pengaruh } \\
\hline Takhayul - produk & 0,67 & 0,82 & 7.78 & Signifikan \\
\hline produk - Kinerja & 0,94 & 0,75 & 4.15 & Signifikan \\
\hline Takhayul - Kinerja & 0,72 & 0,24 & 1,29 & $\begin{array}{l}\text { Tidak } \\
\text { Signifikan }\end{array}$ \\
\hline
\end{tabular}

Sumber: Diolah Peneliti, 2019.

Berdasakan Tabel 1.2. pengaruh langsung antar variabel dari hasil analisis model struktural yang menunjukkan hubungan kausal atau pengaruh satu variabel laten terhadap laten lainnya, dapat dijelaskan sebagai berikut:

Hipotesis H1 - Pengaruh takahyul terhadap produk.

a. Nilai statistik t-hitung 7,78. Hal ini menunjukan variabel takhayul terhadap variabel laten produk memiliki koefisein yang signifikan, karena t-value yang dimiliki $>\mathrm{t}$ tabel $1,96$.

b. Nilai estimasi sebesar 0,82 untuk variabel takhayul terhadap variabel produk $=0,82 \mathrm{X}$ Takhayul. Artinya variabel takhayul secara langsung pengaruhnya sebesar 0,82 terhadap Produk, artinya setiap kenaikan 1 (satu) nilai maka akan terjadi penambahan nilai sebesar 0,81 . Jika diketahui nilai variabel Takhayul adalah 5, maka sumbangsih nilai variabel produk sebesar $0,82 \times 5=41$. Hal ini menunjukkan bahwa variabel takhayul mempunyai pengaruh terhadap variabel produk.

c. Nilai koefisein determinasi $\mathrm{R}^{2}$ sebesar 0,67 . Artinya dapat dikatakan $67 \%$ dari variasi Produk dapat dijelaskan oleh variasi takhayul dan sisanya $33 \%$ disumbangkan oleh variabel lainnya

Hipotesis H2 - Pengaruh produk terhadap kinerja pemasaran.

a. Nilai statistik t-hitung $=4,15$. Hal ini menunjukan variabel produk terhadap variabel laten kinerja pemasaran memiliki koefisein yang signifikan, karena t-value yang dimiliki > t- tabel 1,96.

b. Nilai estimasi sebesar 0,75 untuk variabel produk terhadap variabel Kinerja pemasaran atau kinerja pemasaran $=0,75 \mathrm{X}$ produk. Artinya setiap kenaikan 1 (satu) nilai maka akan terjadi penambahan nilai sebesar 0,75 . Jika diketahui nilai variabel 
produk adalah 5, maka sumbangsih nilai kinerja pemasaran sebesar $0,75 \times 5=$ 3.25. Hal ini menunjukkan bahwa variabel produk mempunyai pengaruh terhadap variabel kinerja pemasaran,

c. Nilai koefisein determinasi $\mathrm{R}^{2}$ sebesar 0,94. Artinya dapat dikatakan $94 \%$ dari variasi kinerja pemasaran dapat dijelaskan oleh variasi produk dan sisanya $6 \%$ disumbangkan oleh variabel lainnya

Hipotesis H3 - Pengaruh takhayul terhadap kinerja pemasaran

a. Nilai statistik t-hitung 1.29. Hal ini menunjukan variabel takhayul terhadap variabel laten kinerja pemasaran memiliki koefisein yang tidak signifikan, karena t-value yang dimiliki > t-tabel 1,96.

b. Nilai estimasi sebesar 0,24 untuk variabel takhayul terhadap variabel Kinerja pemasaran atau kinerja pemasaran $=0,24 \mathrm{X}$ takhayul. Artinya setiap kenaikan 1 (satu) nilai maka akan terjadi penambahan nilai sebesar 0,24. Jika diketahui nilai variabel takhayul adalah 5, maka sumbangsih nilai kinerja pemasaran sebesar 0,24 $\mathrm{X} 5=1.2 \mathrm{Hal}$ ini menunjukkan bahwa variabel takhayul mempunyai pengaruh terhadap variabel kinerja pemasaran,

c. Nilai koefisein determinasi $\mathrm{R}^{2}$ sebesar 0.72 Artinya dapat dikatakan $72 \%$ dari variasi pada Kinerja pemasaran dapat dijelaskan oleh variasi takhayul dan sisanya $28 \%$ disumbangkan oleh variabel lainnya.

\subsection{Pengaruh antar variabel melalui variabel moderasi}

Tabel 3. Pengaruh antar variabel melalui variabel moderasi

\begin{tabular}{|c|c|c|c|c|r|}
\hline Alur & Variabel moderasi & $\left(\mathrm{R}^{2}\right)$ & Direct & Indirect & Total \\
\hline Takhayul - Kinerja & Produk & 0,91 & 0,24 & $0,82 \times 0,75=0,61$ & 0.85 \\
\hline
\end{tabular}

Hipotesis H4 - Pengaruh takhayul berpengaruh terhadap kinerja pemasaran dengan moderasi produk.

Berdasarkan Tabel 3, terdapat pengaruh secara tidak langsung antara variabel takhayul terhadap variabel kinerja pemasaran melalui variabel produk sebesar 0,85 . Hal ini menunjukan bahwa variabel produk memiliki peran yang lebih besar untuk mendukung pengaruh takhayul terhadap kinerja pemasaran. Sedangkan Nilai koefisein determinasi $\mathrm{R}^{2}$ sebesar 0,91. Artinya dapat dikatakan $91 \%$ dari variasi Kinerja pemasaran dapat dijelaskan oleh variasi produk dan takhayul dan sisanya $9 \%$ disumbangkan oleh variabel lainnya

\subsection{Pembahasan}

\subsubsection{Pengaruh Langsung}

Hipotesis H1 - Pengaruh takahyul terhadap produk.

Dari hasil analisis bahwa terdapat pengaruh yang signifikan antara takhayul dengan produk, hal ini didukung oleh penelitian Shum et al, (2013) bahwa nomor apartemen sebagai produk menggunakan angka keberuntungan ada hubungan dengan percaya takhayul. Begitu juga hasil penelitian Selamet dan Tunjungsari, (2012), bahwa terdapat hubungan yang signifikan antara percaya takhayul dengan kesediaan membeli produk mobil warna tertentu. 
Hal ini sangat dipengaruhi oleh kenyakinan pebisnis yang memiliki latar belakang nilainilai budaya dalam keluarga, dimana pebisnis dibesarkan yang percaya pada takhayul, oleh karena itu produk yang akan dipasarkan selalu di kaitkan dengan takhayul, seperti;

a. Bentuk atau model kemasan produk memiliki kesan yang positip.

b. Estika tampilan produk yang dipasarkan memberikan kesan yang positif dan dapat diterima masyarakat, terutama konsumen,

c. Desain kemasan menunjukkan karakteristik dan daya tarik dalam bentuk produk dengan memperhatikan takhayul yang dipercaya oleh pebisnis maupun masyarakat.

d. Simbol bisnis memilik arti membawa keberuntungan, Kemakmuran atau kejayaan

e. Nama merek sebagai tanda kepemilikan, identitas atau mudah untuk mengingat produk yang dipasarkan atau dicari konsumen.

f. Ucapan produk memilik arti keberuntungan, Kemakmuran

g. Warna pada kemasan, bentuk, desain atau tulisan produk yang membawa berkah dikemudian hari

Hipotesis H2 - Pengaruh produk terhadap kinerja pemasaran.

Dari hasil analisis bahwa terdapat pengaruh yang signifikan antara produk dengan kinerja pemasaran, dan didukung oleh penelitian Shum et al, (2013) bahwa percaya takhayul yang menggunakan angka keberuntungan untuk nomor apartemen sebagai produk sangat mempengaruhi penjualan. Hal ini sangat dipengaruhi oleh kenyakinan pemilik bisnis bahwa produk produk yang mudah di ucap, mudah di ingat, memiliki simbol, kemasan dan estika yang menarik serta menunjukkan makna atau image yang positif akan memudahkan konsumen untuk senang kembali melakukan transaksi atau membeli kembali produk yang dijual di bisnisnya yang akan berdampak pada kinerja pemasaran.

Hipotesis H3 - Pengaruh takhayul terhadap kinerja pemasaran

Dari hasil analisis bahwa tidak terdapat pengaruh yang signifikan antara takhayul dengan kinerja pemasan. Hal ini didukung oleh penelitian Alias et al, (2014), bahwa takhayul tidak mempunyai pengaruh langsung terhadap kinerja pemasaran. namun perlu variabel moderasi sebagai trigger.

\subsubsection{Pengaruh tidak langsung}

Hasil analisis terdapat pengaruh antara takhayul dengan kinerja pemasaran dengan variabel moderasi Produk. Hal ini sesuai dengan hasil penelitian Evgeny dan Pokryshevs (2015) dan Shum et al, (2013) kenyataannya terdapat pengaruh antara takhayul dengan peningkatan volume penjualan yang menggunakan angka keberuntungan atau simbol angka pada nama apartemen sebagai variabel moderasi. Hal ini menunjukkan bahwa pemilik usaha yang nyakin dalam meningkatkan kinerja pemasaran, membutuhan takhayul sebagai mediasi yang dijemahkan dalam bentuk ;

a. Percaya pada keberuntungan, apabila menggunakan simbol atau angka untuk produk yang membawa keberuntungan atau kemakmuran yang dipengaruhi oleh lingkungan keluarga , masyarakat atau kepercayaan yang dinyakinkan.

b. Percaya ritual takhayul yang dipengaruh masyarakat atau keluarga dengan melakukan ritual, seperti melakukan doa bersama atau syukuran untuk produk yang 


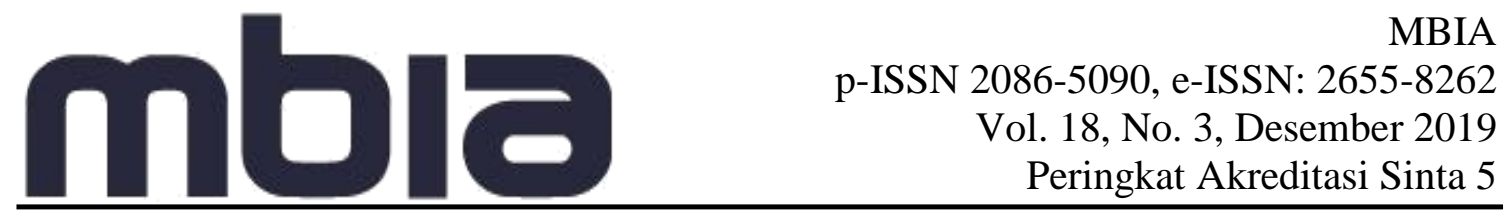

dipasarankan sebagai daya tarik konsumen agar tercapai ekspektasi tingkat volume penjualan, laba penjualan serta bisnis yang berkelanjutan.

c. Melakukan konsultasi kepada dukun dengan menggunakan produk yang meliputi merek, warna dan kemasan sebagai sarana perantara agar bisnis berjalan lancar dan mendatangkan laba.

d. Pebisnis nyakin bahwa kinerja pemasaran dalam meneningkatan valume penjualan, pertumbuhan konsumen dan keuntungan tidak dapat dikaitkan langsung dengan tahayul tanpa sarana atribut yang melekat pada produk.

\section{Simpulan}

Pengaruh satu variabel dengan variabel lainnya terbukti positif dan signifikan, yaitu; (a) Variabel takhayul berpengaruh positif terhadap produk, Hal ini dapat dilihat pada item kenyakinan pemilik bisnis atau pengusaha dengan latar belakang budaya atau keluarga yang percaya pada takhayul, maupun pebisnis memanfaatkan pelanggan yang percaya takhayul sebagai pengambil keputusan membeli produk yang ditawarkan, seperti pada merek dagang, produk yang menggunakan kemasan, kalimat yang memiliki makna, simbol, ucapan dan warna yang akan mendatangkan keberuntungan bagi pemilik bisnis; (b) Variabel produk berpengaruh positif terhadap kinerja pemasaran. Hal ini dapat dilihat pada item produk yang mudah di ucap, mudah di ingat, memiliki simbol, makna atau image yang positif akan memudahkan konsumen untuk senang kembali melakukan transaksi atau membeli kembali produk yang dijual di bisnisnya yang akan berdampak pada kinerja pemasaran; (c) Variabel Takhayul berpengaruh negatif terhadap kinerja pemasaran, kecuali Takhayul berpengaruh positif terhadap kinerja pemasaran dimoderesi variabel produk. Hal ini menunjuk bahwa pebisnis yang percaya takhayul dapat meningkatkan kinerja pemasaran membutuhkan sarana perantara yaitu variabel produk dalam penelitian ini.

\section{Daftar Pustaka}

Evgeny, A. Antipov dan B Elena Pokryshevskaya, (2015). Are Buyers of Apartments Superstitious? Evidence from the Russian real estate market, Journal of Judgment and Decision Making. ISSN 1930-2975. Vol.10 No.6 pages 590-592.

Fortin, Nicole M, Andrew J. Hill, dan Jeff Huang. (2014). Superstition in the Housing Market, economic Inquiry, Vol.52 Issue 3, pages 974-993.

Grønholdt L dan Martensen, A. (2006). Key Marketing Performance Measures. The Marketing Review, Vol. 3, pages 243-252.

Gronroos, Christian. (2011). Service Management and Marketing: Customer Management in Service Competition, 3rh ed. John Wiley and Sons.

Alias A; Hamsani D.F; S.J.L. Chua dan S.M Zaid. (2014). Psychologically Impacted Houses-Superstitions and Marketability Problems, Journal of Building Performance. ISSN: 2180-2106. Vol.5 no 1 pages 34-48

Hogendoorn, Willem. 1993. Paranormal: Kenyataan dan Gejala dalam Kehidupan, Dahara Prize, Semarang.

Kaur, Jaspreet dan Chawla, Roopkamal. 2016. Impact Of Culture on Marketing Strategies, Imperial Journal of Interdisciplinary Research (IJIR), ISSN: 2454-1362. Vol 2, Issue 3.

Koentjaraningrat. 2013. Pengantar ilmu Antropologi, Cetakan ke IX penerbit Aksara Baru, Jakarta. 


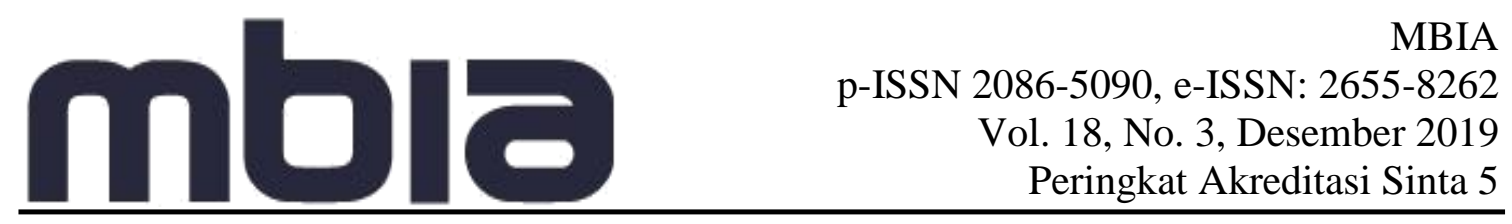

Kotler, Philip dan Keller Kevin Lane. 2012. Manajemen Pemasaran (Edisi ketiga Belas), Cetakan Ketiga: PT. Indeks. Jakarta.

Kramer, Thomas dan Lauren, Block. 2008. The effect of Superstitious Beliefs on Performance Expectations. Journal of Academy of Marketing Science, ISSN15527824. Vol. 37 pages 161-169.

Levitt, E. E. (1952). Superstitions: twenty-five years ago and today. The American Journal of Psychology, ISSN 1939-8298. Vol. 65(3), pages 443-449.

Sen, Mehmet dan Ezgi Yesilyurt. (2014). The Development of the Paranormal Belief Scale (PBS) for Science Education in the Context of Turkey. International Journal of Education in Mathematics, Science and Technology, ISSN 1464-5211. Vol. 2, No.2, Pages 107-115.

Sekaran, Uma dan Bougie Roger, 2013. Research Methods For Business: A Skill-Building Approach.Sixth Edition, United Kingdom: John Wiley \& Sons Ltd.

Selamet, Franky dan Tunjungsari, H.Karunia. (2012). Pengaruh Takhayul terhadap Kesediaan Memberi yang Dimoderasi oleh Informasi Produk.. NCFB-V-FBUniversitas Katolik Widya Mandala-Surabaya,ISSN: 1978-6522. Vol.5 pages 292302

Shum, Matthew; Wei Sun dan Guangliang Ye. 2013. Superstition and Lucky apartments; Evidence from transaction- level data, Journal of Comparative Economics, ISSN: 0147-5967.Vol 42 Issue.1, pages 109-117.

Stanton, William J. (2008). Fundamental of Marketing, Mc. Graw Hill Inc

Wang, Jian Yong; M.D Hernandez; M.S. Minor dan Jie Wei. (2012). Superstitious Belief in Consumer Evaluation of Brand Logos. Europen Journal of Marketing. ISSN: 0309-0566 Vol 46 No.5 pages 713-732.

Wang, Y; Goodfellow R and Zhang X. (2000). Business Culture China, diterjemah; Soetikno, J, Penerbit Kepustakaan Populer Gramedia.

https://kaltim.tribunnews.com/2015/10/15/tak-sekedar-lafaz-allah-ternyata-motifsandal-ini-kaligrafi-al-ikhlash?

\section{Copyright Disclaimer}

Copyright for this article is retained by the author(s), with first publication rights granted to the journal. 